\title{
Astronomy as a School Subject
}

\author{
By J-L. Fouquet \\ 18, Rue de Puits de Fev, 17630-La Flette, France
}

\section{A brief survey about the teaching of astronomy in France at Primary and Secondary School level}

a) From 9 to 11, a "Science and Technology" curriculum is extensively provided by primary schools :

"Pupils, through some aspects of the scientific approach, are encouraged to develop their abilities to formulate questions and logical answers through a wide scope of investigative and practical observations and other scientific activities such as collecting measures, linking data, interpreting documents"- extract from the official syllabus which includes the following chapters :

1. Unity and Diversity of the Living World :

- the development of living creatures,

- animal reproduction,

- human sexuality,

- ecology,

- nutrition.

2. The Human Body and Health Education :

- sports,

- hygiene,

- nutrition,

- first aid.

3. The Sky and the Earth :

- the earth movements / revolutions,

- the solar system,

- the universe,

- light and shadow,

- calendars,

- sundials.

4. Energy and Matter :

- the cycle of water,

- the quality of air,

- energy : providing and saving energy.

5. Objects and Technological Projects :

- wire connections,

- mechanical and electrical devices,

- models.

6. Computer Science :

- using software within the scope of school subjects.

Officially, this programme should be divided into 72 periods of one hour and a half each. In actual practice, about 200 hours are devoted to partly cover the teaching of science, among which 20 hours, spread over two years, deal with astronomy.

In most primary schools, teachers are obviously the main suppliers of information, and they do so according to their own preferences and abilities. Nevertheless, teachers, as individuals or as members of the teaching team, can always ask a qualified speaker from 
outside the school to take part in the teaching / learning process. It is within this specific framework that I have been able to teach astronomy in various schools in the area where I teach physics, and this for more than 10 years, now, mostly dealing with children from 9 to 11 .

b) At Secondary School level :

- from 11 to 13 : physics and astronomy are no longer taught.

- from 13 to 15 : physics is taught by a qualified teacher 2 hours a week. During those two years, no more than 10 hours can be devoted to astronomy.

\section{What is the common ground between Primary and Secondary Schools?}

The first thing we should emphasize is the major importance of inquisitive thinking and scientific questioning at the earliest age possible ...

... as early as nursery school, when children are full of enthusiasm, eager to communicate and imaginative, when they are always ready to listen to fairy tales, sing a "ring-a-ring-a-roses", dance and play in circles, create stories and draw.

$\ldots$ and until they are about 10 and have still got a natural curiosity that they will unfortunately lose a few years later when they will start feeling conscious and ashamed of their body, under other people's eye.

Then, the astronomer should go to school and meet the children there, on a very regular basis, for a period of at least a few weeks.

There should be, well in advance, some kind of preparation shared with the teacher in charge, so that the long term objectives of the project, its different steps and the final evaluation of the achievements are outlined long beforehand.

The various sessions can be varied :

- indoors : movies, slides, models, balls, lights can be used.

- outdoors : observation of the moon, shadows, sunspots; dancing in rings to imitate the moon, earth revolutions and the solar system.

- in magic meeting points : such as a planetarium, an exhibition or "discovery classes" wher magic meetings can happen with a real genuine astronomer for example.

We should take into account the initial interpretation of children. We can, at a certain point, accept a child's inaccurate representation with some kind of reservation, as long as we can slowly improve its accuracy through discussions, observations... Otherwise, pupils will become passive.

Let's take an example with the annual earth revolution and the cycle of the seasons : A set of slides illustrating the above activities at school were shown.

- number 1 : Experiment with the help of a globe and a spotlight to exclude possibilities. The northern hemisphere would always experience summer! See Fig. 1.

- number 2: Statement : the Pole Star is fixed as are the other stars.

- number $3: 4$ tennis balls and 4 parallel strings long enough to show that the earth axis always points towards the Pole Star. See Fig. 2.

Finally, we should offer a lot of books to read to young children. Avoid encyclopedias, which are too compact, and books with too many beautiful illustrations or already solved problems. We should always prefer books or, for younger ones, tales that lead to new tracks, awaken curiosity and initiate discussion. Reality and fiction will be divided as such, later on, when and if necessary.

A set of slides illustrating the above were shown. 


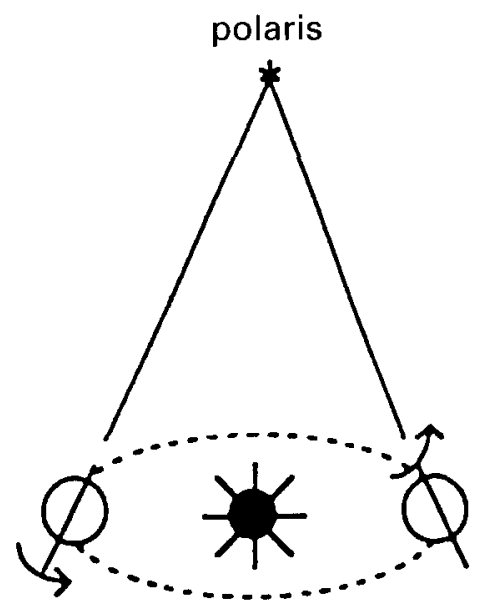

Figure 1.

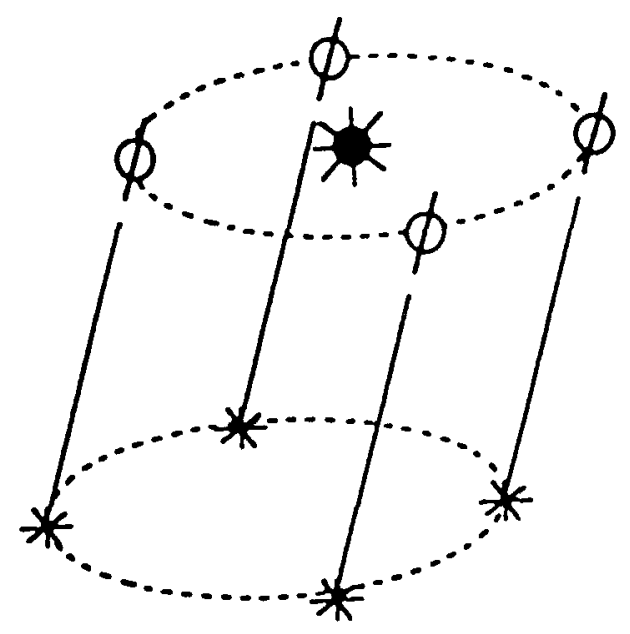

Figure 2. 